\title{
Energy saving potential of fragmented green spaces due to their temperature regulating ecosystem services in the summer
}

Fanhua KONG ${ }^{1, *}$, Changfeng SUN ${ }^{1}$, Fengfeng LIU ${ }^{1}$, Haiwei YIN ${ }^{2}$, Fei JIANG ${ }^{1}$, Yingxia PU $^{3}$, Gina CAVAN ${ }^{4}$, Cynthia Skelhorn ${ }^{5}$, Ariane Middel $^{6}$, Iryna Dronova ${ }^{7}$

${ }^{1}$ International Institute for Earth System Science (ESSI), Nanjing University, Xianlin Ave.163, 210023, Nanjing, China;

${ }^{2}$ Department of Urban Planning and Design, Nanjing University, No. 22, Hankou Road, 210093, Nanjing, China;

${ }^{3}$ Department of Geographical Information Science, Nanjing University, Xianlin Ave.163, 210023, Nanjing, China;

${ }^{4}$ Division of Geography and Environmental Management, School of Science and the Environment, Manchester Metropolitan University, Manchester, UK, M1 5GD;

${ }^{5}$ School of Environment and Development, University of Manchester, Oxford Road, Manchester M139PL, United Kingdom.

${ }^{6}$ School of Geographical Sciences and Urban Planning, Arizona State University, Tempe, AZ 85287, United States

${ }^{7}$ Department of Landscape Architecture and Environmental Planning, University of California at Berkeley, Berkeley, CA 94720, United States

This is the accepted version of the article that appears in Applied Energy:

F. Kong, C. Sun, F. Liu, H. Yin, F. Jiang, Y. Pu, G. Cavan, C. Skelhorn, A. Middel, I.

Dronova, (2016). Energy saving potential of fragmented green spaces due to their temperature regulating ecosystem services in the summer. Applied Energy. 183, pp.1428-1440. 


\title{
Highlights
}

- The thermal environment was simulated with a validated ENVI-met model.

- Daily 3D spatial temperature variation was identified with and without green spaces.

- Green spaces below mean building height provided variable cooling benefits.

- The temperature reduction through fragmented green spaces was translated into cooling energy equivalents.

\begin{abstract}
Urban green spaces help to moderate the urban heat island (UHI) effects, and can provide important temperature regulating ecosystem services and opportunities for savings in cooling energy. However, because explicit market values for these benefits are still lacking, they are rarely incorporated into urban planning actions. Green spaces can generate a threedimensional (3D) cool island that may reduce the cooling energy requirements within and around urban areas, but such 3D cooling effect has not been considered in previous studies quantifying energy savings from green spaces. This study presents a new and simple approach to quantify potential energy savings due to the temperature regulating ecosystem services of small-scale fragmented green spaces using the 3D simulation of the summer-day outdoor thermal environment in Nanjing, China. Field survey data and the microclimate model ENVI-met were applied to examine the outdoor 3D thermal environmental patterns at Gulou Campus of Nanjing University under two different scenarios: "with" and "without" green spaces. Modeling results were applied to quantify potential cooling energy savings based on the effect of green spaces on the outdoor urban environment and to calculate the cumulative temperature reduction due to green spaces using a regression model. The results show that, in the horizontal direction, the simulated distribution of wind speed and mean air temperature at $1.5 \mathrm{~m}$ height were closely related to the spatial distribution of the underlying surface types. Removal of green spaces increased mean air temperature by $0.5^{\circ} \mathrm{C}\left(33.1^{\circ} \mathrm{C}\right.$ vs. $33.6^{\circ} \mathrm{C}$ ). In the vertical direction, removal of green spaces had little effect on the near-surface wind field; however, above the surface, the turbulence perpendicular to the main wind direction significantly increased. Quantification of the cooling benefits of green spaces in relation to the mean height of buildings on Gulou Campus yielded $5.2 \mathrm{~W} / \mathrm{m}^{2}$ cooling energy, saving totally $1.3 \times 10^{4} \mathrm{~kW}$ h during a single daytime hot summer period. This case study corroborates the importance of green space for cooling and informs city planners and decision-makers on how microclimate is impacted by the loss of green spaces. These findings will facilitate preservation, planning, and design of green spaces to increase urban environmental benefits and to improve the microclimate of urban areas at neighborhood, city, and regional scales.
\end{abstract}

\section{Keywords}

- Green space;

- Energy saving;

- ENVI-met model;

- Temperature regulating ecosystem services;

- Urban heat island;

- 3D-thermal environment 


\section{Introduction}

Urban heat islands (UHIs) increase cooling energy consumption in urban areas during summer [1], [2], [3], [4], [5] and [6]. Consequently, a major focus of UHI research has been to identify the most effective mitigation strategies to reduce the demand for cooling energy [7], [8], [9], [10] and [11]. Previous studies have shown that green spaces cool the built environment through shading and evapotranspiration and thus provide an important ecosystem service of temperature regulation [12], [13], [14] and [15]. As a result, it has been suggested that the area and density of tree cover should be increased to reduce and alleviate the negative impacts of the UHI, which, in turn, would save energy [16], [17], [18], [19], [20], [21] and [22]. The air cooled by green spaces accumulates to form a three-dimensional (3D) urban cool island that can reduce cooling energy demand within and around urban areas [12], [2], [23], [24], [25], [26] and [27]. Thus, green spaces may act as natural air conditioning and save building energy, especially during the hotter summer daytime [28], [29], [30], [31] and [32]. However, most studies to date have only examined the cooling effect of green spaces and changes in air temperature across horizontal scales [12], [23] and [24], while the potential to save energy via 3D (both horizontal and vertical) cooling has not been studied extensively. Most studies on the cooling effect of green spaces have focused on the direct indoor energy savings due to the surrounding outdoor vegetation and roof and wall greenery using simulations or real-world data [33], [34], [35], [36] and [37]. Few studies have quantified the extent of these cooling services at the scale of a single green space patch or several patches. In particular, the collective net cooling services provided by fragmented green spaces in the $3 \mathrm{D}$ domain have not been investigated.

The urgent need to address this knowledge gap is further underscored by the continuous threat of reduction and fragmentation of green spaces in urban areas. The benefits of urban green spaces are non-marketable goods that cannot be directly traded [36], [38] and [39]. Evaluating these cooling services and microclimate regulation can elucidate the potential for building energy savings and thus provide essential information for urban planning and design [40]. Since quantifying the cooling services of fragmented green spaces in 3D is an ongoing challenge, these benefits are often overlooked by urban planners. Consequently, urban green spaces have been gradually encroached upon by urban development, resulting in further reduction in their size or complete loss [41].

There is a saying: "People often don't appreciate what they have until they lose it." Thus, the best way to quantify the roles and values of fragmented green spaces in regulating thermal environments is to assess the characteristics of built-up areas without vegetation. Developing scenarios of urban areas with and without green spaces can demonstrate the value of green spaces, and, if supported by scientific evidence, can contribute to their protection and management. Previous studies have also shown that the composition and spatial arrangement of green spaces, as well as land-use and building patterns, influence urban microclimates [24], [42], [43], [44], [45], [46], [47] and [48]. Hence, scenario analysis may help identify the value of green spaces as cooling services, leading to better planning and decision-making for these sites [49].

Microclimate models are particularly suited to perform 3D numerical simulations to conduct spatio-temporal analyses of thermal environments at different scales [11] and [27]. In particular, the ENVI-met 3D computational fluid dynamics model has been used in various studies to simulate the impact of vegetation on microclimate in cities [15], [30], [49], [50], [51], [52], [53] and [54]. Most of these studies have also evaluated 
the overall performance of ENVI-met and confirmed that it can model outdoor thermal environments under different climate patterns with acceptable accuracy [52], [55] and [48].

Using the ENVI-met model, this study develops a new and simple approach to quantify potential energy savings due to temperature regulating ecosystem services of small-scale fragmented green spaces. We conducted a case study at Gulou Campus of Nanjing University, China to compare outdoor 3D thermal environmental patterns during the daytime for a typical summer day under two scenarios: current scenario "with" green spaces (replicating the actual conditions of the campus) and designed scenario "without" green spaces. We validated the ENVI-met modeling results using in-situ meteorological measurements and then simulated the campus' 3D microclimate. We then analyzed the outputs to investigate the impact of green spaces on the campus microclimate and quantified the energy savings of small-scale fragmented green spaces. Finally, we evaluated the energy savings of green infrastructure based on the meteorological simulation results. Although there have been many studies on the cooling effects or energy savings of green spaces, this research is one of the first examples where cooling effects and energy savings of green spaces are analyzed together in 3D space.

Our results will inform urban designers, city managers, and planners on how removal or loss of green space may alter the local microclimate and thermal regulation of an urban site. This information is needed to better understand the microclimatic significance of green spaces and to guide future conservation, planning, and design of these areas to enhance their environmental benefits and improve the microclimate at the neighborhood, city, and regional scales.

\subsection{Methods}

\subsection{Study site description}

The study was conducted in Nanjing ( $\left.31^{\circ} 14^{\prime \prime}-32^{\circ} 37^{\prime \prime} \mathrm{N}, 118^{\circ} 22^{\prime \prime}-119^{\circ} 14^{\prime \prime} \mathrm{E}\right)$, the second largest city in eastern China with a population of over 6.3 million within a $4723 \mathrm{~km}^{2}$ area [56]. Nanjing has a humid sub-tropical climate with hot and humid summers. Heat waves (defined as three consecutive days when the temperature is $\geqslant 35^{\circ} \mathrm{C}$ ) are common, with 112 heat waves recorded between 1951 and 2009 [57]. The highest recorded temperature was $43{ }^{\circ} \mathrm{C}$ in July 1934.

The Gulou Campus of Nanjing University is located in the downtown of Nanjing city, with most trees on campus being preserved since the university was founded in 1902 (Fig. 1). The selected study area is 25.56 ha, with buildings and green areas covering 6.49 ha $(25.4 \%)$ and 7.67 ha $(30 \%)$, respectively. The vegetation is diverse, with the main tree species including Platanus hispanica, Metasequoia glyptostroboides, Platycladus orientalis, Ginkgo biloba L., Buxus sinica, and Pittosporum tobira. 
Six sites on campus were chosen for meteorological data collection based on the differences in their land surface characteristics (see Table 1 for descriptions; see Figure 1 for locations).
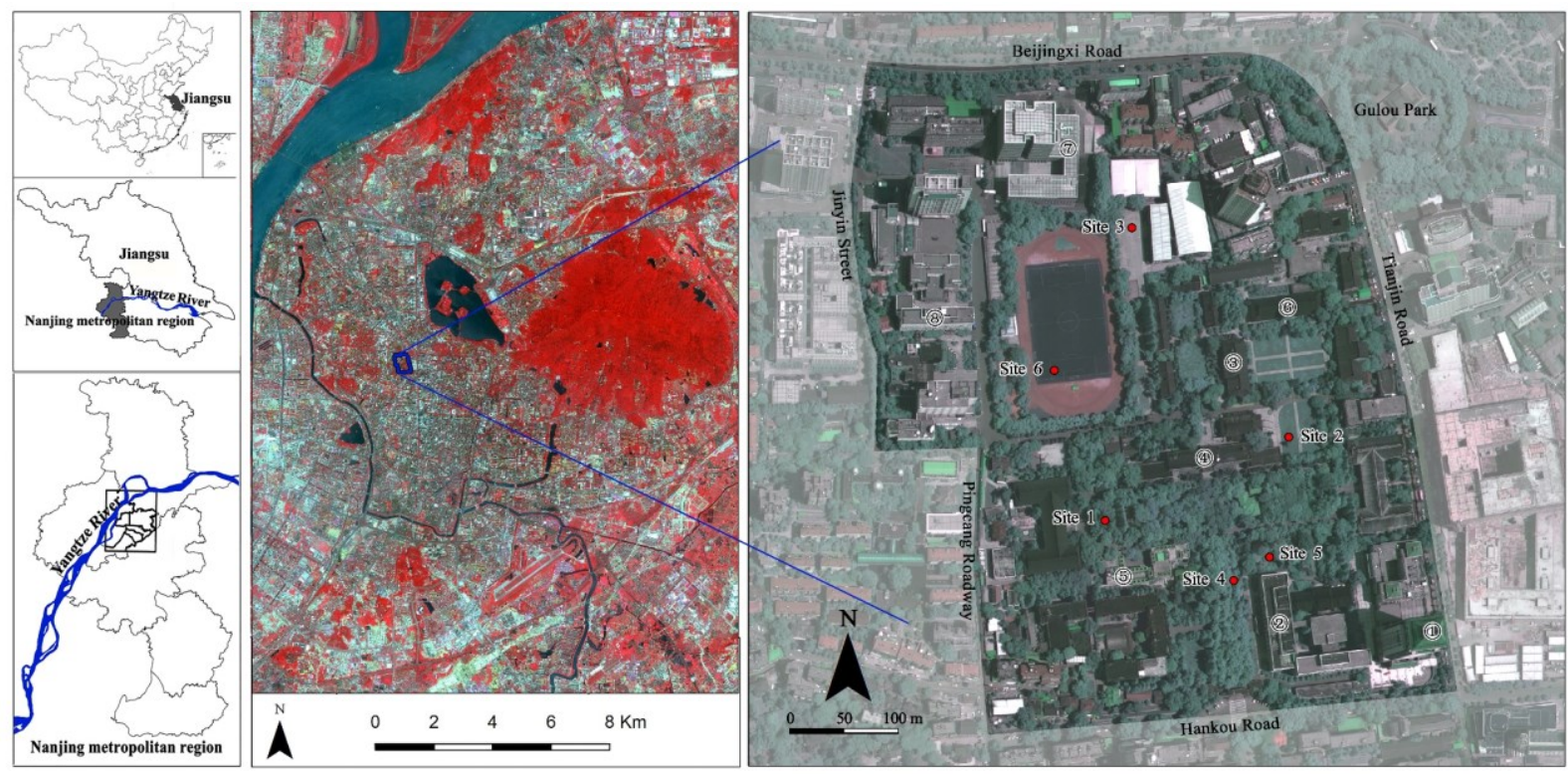

Fig. 1. Location of the study area (a), the on-site field measurement points (site1-site 6) in Gulou campus of Nanjing University (b), and (1)-(6) landmarks in the campus (1)Mengminwei B., (2)Library B., (3)Xinan B., (4)Teaching B., (5)Zhixing B., (6)Beida B., (7)Feiyimin B., (8)Art Science B.)

Table 1. Location and characteristics of selected measurement sites

\begin{tabular}{lllc}
\hline Location & Description (landmark) & Shade & Land surface types \\
\hline Site 1 & Forest (near the Bainianding) & Yes & grass (sparse) \\
Site 2 & Lawn (in front of the Auditorium B.) & No & grass \\
Site 3 & Concrete road (in front of the Aquatic center B.) & No & concrete \\
Site 4 & Avenue (Zhongda R.) & Yes & asphalt \\
Site 5 & Shrub (behind the Library B.) & No & shrub-grass \\
Site 6 & Artificial grass (in the Playground) & No & artificial grass \\
\hline
\end{tabular}

\subsection{Field measurements}

Microclimate measurements were performed during July 14-19, 2013, and the data from July 18 with the most stable weather conditions were selected for this study. The following meteorological variables were recorded by $\mathrm{HOBO}(\mathrm{U} 30$ and $\mathrm{H} 21)$ meteorological stations at a height of $1.5 \mathrm{~m}$ : air temperature $\left(\mathrm{T}_{\mathrm{a}}\right)$, global solar radiation $(\mathrm{SR})$, relative humidity $(\mathrm{RH})$, wind speed (WS), and wind direction (WD). The sensor parameters of the HOBO station are summarized in Table 2. All the data were recorded at 1-min intervals and stored in a data logger. Six total HOBO meteorological stations were used, with one station in each of the six measurement sites. 
Table 2 Sensor parameters of the HOBO automated meteorological observation stations.

\begin{tabular}{lllll}
\hline Smart Sensors & Product Model & Supported Measurement & Accuracy & Resolution \\
\hline Wind Speed and Direction & S-WCA-M003 & Wind speed & $\pm 0.5 \mathrm{~m} / \mathrm{s}$ & $0.19 \mathrm{~m} / \mathrm{s}(0.42 \mathrm{mph})$ \\
Smart Sensor & & Wind direction & \pm 5 degrees & 1.4 degrees \\
Temperature/RH Smart & U23 & Temperature & $\pm 0.2^{\circ} \mathrm{C}\left(25^{\circ} \mathrm{C}\right)$ & $0.02^{\circ} \mathrm{C}\left(25^{\circ} \mathrm{C}\right)$ \\
Sensor & & Relative humidity & $\pm 2.5 \%$ & $0.03 \%$ \\
Photosynthetic Light (PAR) & S-LIA-M003 & Light intensity & $\pm 5 \mathrm{umol} / \mathrm{m}^{2} / \mathrm{sec}$ & $2.5 \mathrm{umol} / \mathrm{m}^{2} / \mathrm{sec}$ \\
Smart Sensor & & & & \\
Solar Radiation Sensor & S-LIB-M003 & Light intensity & $\pm 10 \mathrm{~W} / \mathrm{m}^{2}$ & $1.25 \mathrm{~W} / \mathrm{m}^{2}$ \\
\hline
\end{tabular}

\subsection{ENVI-met model setup}

\subsubsection{Data used for model geometry settings}

The ENVI-met model requires a user-specified area input file that defines the 3D geometry of the built environment. In this study, the simulated domain was constructed based on a QuickBird satellite image taken in 2011 at a resolution of $0.61 \mathrm{~m}$. The digital elevation model (DEM) of the study area and the height of all buildings and trees were extracted from LiDAR data.

\subsubsection{Model parameterization and setup}

The ENVI-met model was initially parameterized based on geometry and field measured characteristics of the actual site. Horizontally, a grid of $230 \times 230$ cells was created over the entire model area at $3 \mathrm{~m}$ resolution $(690 \mathrm{~m} \times 690 \mathrm{~m})$. The vertical grid cell size was set to $7.5 \mathrm{~m}$. ENVI-met automatically subdivided the lowest grid box above the surface into five layers of $1.5 \mathrm{~m}$ height each, which yields a model height of $225 \mathrm{~m}$ for a total of 34 grid cells $(5 * 1.5 \mathrm{~m}+29 * 7.5 \mathrm{~m})$. In addition to the core model area defined in the area input file, ENVI-met created an area of nested grid cells around the main area to move the model boundary away from the area of interest and to minimize boundary effects [58]. The nested area is a band of grid cells surrounding the 3D model core, and is the buffer zone of the model. The further the cells move away from the model core, the larger the nested area becomes, making it possible to move the model boundaries away from the core without excessive loss of calculation accuracy. Srivanit and Hokao [30] added 65 nested grid cells (or $195 \mathrm{~m}$ ) to the initial model domain in their studies on the environmental effects of green space, and found that the added nested grid cells greatly improved the accuracy of the ENVImet model. However, the number of nested grid cells in the modeled area was constrained to our study area's limit of $250 \times 250 \times 30$ grid cells. Moreover, the nested grid cells have an optimal nesting size at which simulation accuracy remains constant, even if the number of nested grid cells is further increased. Considering this limitation, we empirically determined that 9 nested grid cells (or $27 \mathrm{~m}$ ) on each side would be optimal to greatly increase the numerical stability and accuracy of the simulation for objects close to the study area boundary. Considering built-up land and green space around the core region, the nested grid surface was set to a chessboard pattern of two soil profiles, loam, and asphalt.

The height of the tallest building (the Mengmingwei B.) in our study area was $113.6 \mathrm{~m}$, which ensured that the upper boundary height of the 3D model approximately met the $\mathrm{z} \geqslant 2 \mathrm{Hmax}$ (maximum building height) requirement. In addition, the model area was rotated $8.7^{\circ}$ away from grid north to minimize problems arising from the rectangular grid of the model [59]. The height values of grass and shrubs were set to $0.05 \mathrm{~m}$ and $1.3 \mathrm{~m}$, respectively. 
The most frequent wind direction at the six sites was selected as the prevailing wind direction $\left(180^{\circ}\right.$, south wind). The wind speed data were recorded $10 \mathrm{~m}$ above the ground at the local weather station. Validation experiments of the ENVI-met model by Ali-Toudert [60] and Chow and Brazel [61] showed that the model has a tendency to underestimate air temperature during the daytime. Therefore, to improve the simulation accuracy, the initial temperature was estimated as the mean air temperature of the six sites at 05:00 h on July 18, 2013. The cyclic type was selected for the Lateral Boundary Conditions (LBC), because the study area is located in the city center where the neighborhood space layout is similar to the campus. The air temperature in the buildings was set to $26^{\circ} \mathrm{C}$ based on the building management system records. Thermal properties of building envelopes were derived from the local "thermal design code for civil buildings" (GB50176-93) [62] and referenced to the material database of Yang et al. [63].

The duration of ENVI-met model simulations can vary between a couple of hours to several days and weeks depending on the simulation time, size and complexity of the model area, and computational power. Since the input area for this study was close to the maximum allowed size and included complex land-use and building patterns, the simulation was run for $12 \mathrm{~h}$, from $05: 00 \mathrm{~h}$ to $17: 00 \mathrm{~h}$ for July 18,2013 , to reduce the computation time.

\subsubsection{Quantitative evaluation of the ENVI-met model}

The simulated hourly air temperatures at $1.5 \mathrm{~m}(05: 00 \mathrm{~h}$ to 17:00 h) were extracted for each of the six sites and compared with the HOBO observations to assess the accuracy of the ENVI-met model. To quantify the agreement between the simulated and observed micrometeorological values (wind, humidity, and air temperature), we estimated different measures suggested by Willmott [64] and used statistical correlation metrics to describe the extent of error in the model prediction and the main sources of error. Because this study focused on the regulation of air temperatures in green spaces, only simulated and observed air temperatures were compared. To assess the cooling potential due to vegetation at the landscape scale of the study area, two scenarios were developed: current scenario (Fig. 2a) representing the actual landscape composition of the study area, and designed scenario, in which all of the fragmented green spaces were removed (Fig. 2b).

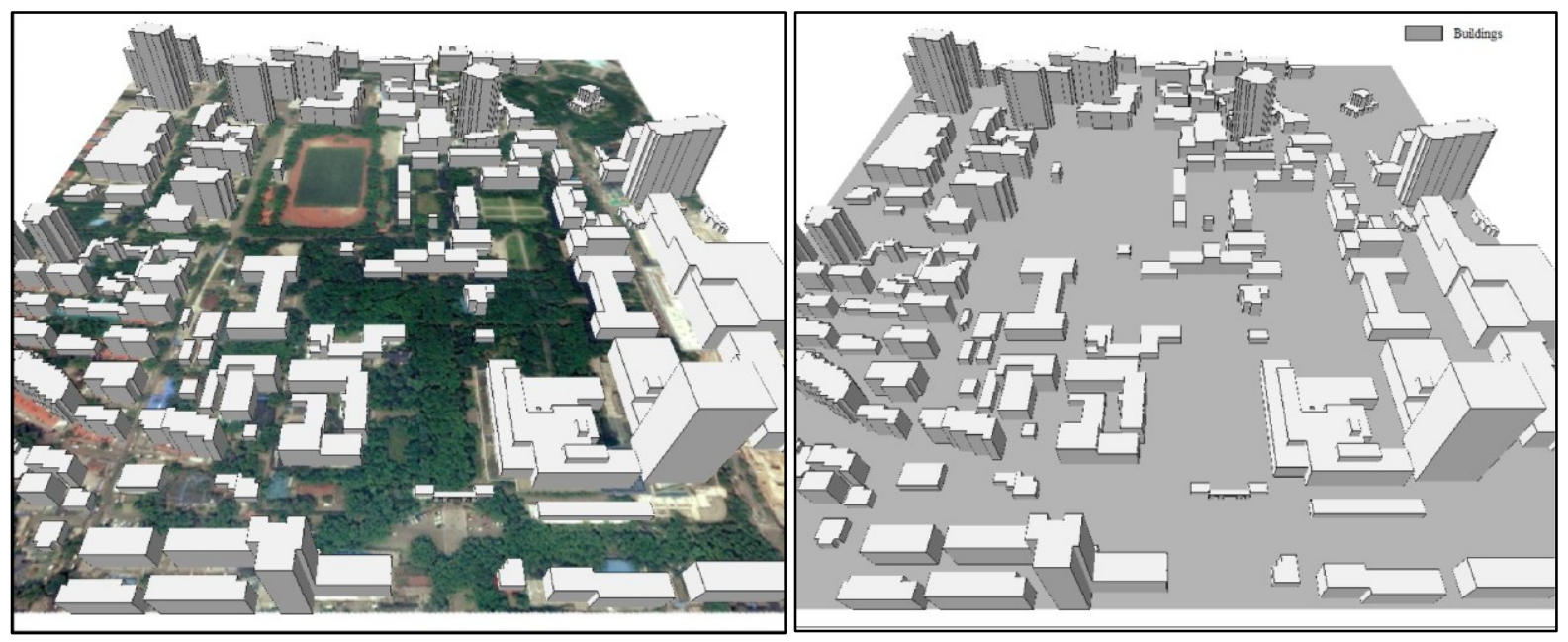

Fig. 2. Three dimensional diagram of the Gulou campus: a) the current scenario, b) the design scenario (without green spaces) 


\subsubsection{Quantifying potential energy savings by fragmented green spaces}

To quantify the cooling effects of green spaces, suitable vertical boundary conditions must be assumed. Previous assessments of the energy saving potential due to the presence of trees primarily focused on tree shade without considering evapotranspiration and thus used tree height to define the vertical boundary [2] and [65]. However, microscale, site-specific characteristics and processes also control airflow and energy exchange in the urban canopy layer (UCL, roughly from ground to roof level) [66]. To calculate the energy savings by fragmented green spaces of the campus, it was first necessary to determine the vertical height appropriate for the study's research objective. To this end, the spatial variation of the daily thermal 3D environment was evaluated based on the ENVI-met model simulation output of the "with" or "without" green space scenarios. Changes in the daily mean vertical air temperature gradient were then quantified for both scenarios using regression, yielding the functions $f(h)$ and $g(h)$, where $h$ is the height above ground level and $f(h)$ and $g(h)$ represent the daily mean air temperature at height $h$ for the "with" and "without" green space scenario, respectively. The daily mean cumulative 3D temperature reduction $\Delta \mathrm{T}_{\mathrm{h}}$ generated by the green spaces from the ground level to height $\mathrm{h}$ was then calculated by integrating over the developed regression models: equation(1)

$\Delta \mathrm{T}_{h}=\int_{0}^{h}[g(h)-f(h)] d h$

where $h$ is the height above ground level; $f(h)$ and $g(h)$ are daily mean air temperatures at the height of h estimated using a regression model developed from the output simulation results; $\Delta \mathrm{T}_{\mathrm{h}}$ is the daily mean cumulative reduction in temperature from the ground level to height $h$.

Thus, at the height of $\mathrm{h}$ in the study area, by comparing the difference between the "with" and "without" green space scenarios, the daily mean energy savings from the vegetation cooling effect were subsequently calculated by the following statistical model:

equation(2)

$\Delta \mathrm{Q}_{h}=c m \Delta \mathrm{T}_{h}=c \rho s \int_{0}^{h}[g(h)-f(h)] d h$

where $\Delta \mathrm{Q}_{\mathrm{h}}$ is the heat difference between the current and designed scenario from ground level to a height of $\mathrm{h}, \mathrm{c}$ is the specific heat capacity $\left(1.0 \times 10^{3} \mathrm{~J} / \mathrm{kg}{ }^{\circ} \mathrm{C}\right), \rho$ is the air density $\left(1.29 \mathrm{~kg} / \mathrm{m}^{3}\right)$, and $\mathrm{s}$ is the size of the study area excluding the built up areas.

\section{Results and discussion}

\subsection{ENVI-met model evaluation}

Overall, strong agreement and similar daytime dynamics $(05: 00 \mathrm{~h}$ to 17:00 $\mathrm{h})$ were found between the HOBO observations and simulated hourly air temperatures at $1.5 \mathrm{~m}$ for each of the six sites (Fig. 3). Modeled and observed air temperatures strongly correlated at all sites, except for a few disparities at sites 5 and 6 (Fig. 3). For site 5 (shrub) (Fig. 1b), the modeled temperature was higher than the observed after 12:00 h. The largest recorded temperature difference was $1.8^{\circ} \mathrm{C}$ at 13:00 $\mathrm{h}$, because a nearby building to the south, Library B., cast a shadow, cooling the air temperature more pronounced than the simulation shows. For site 6 (playground), the difference between measured and modeled temperatures became significant 
after 09:00 $\mathrm{h}$ and peaked at 15:00 $\mathrm{h}$, the hottest time of the day, with a $3.1^{\circ} \mathrm{C}$ lower simulated air temperature. This difference could result from playground's location in a lower-elevation portion of the study area, although our study did not specifically consider topographical effects.
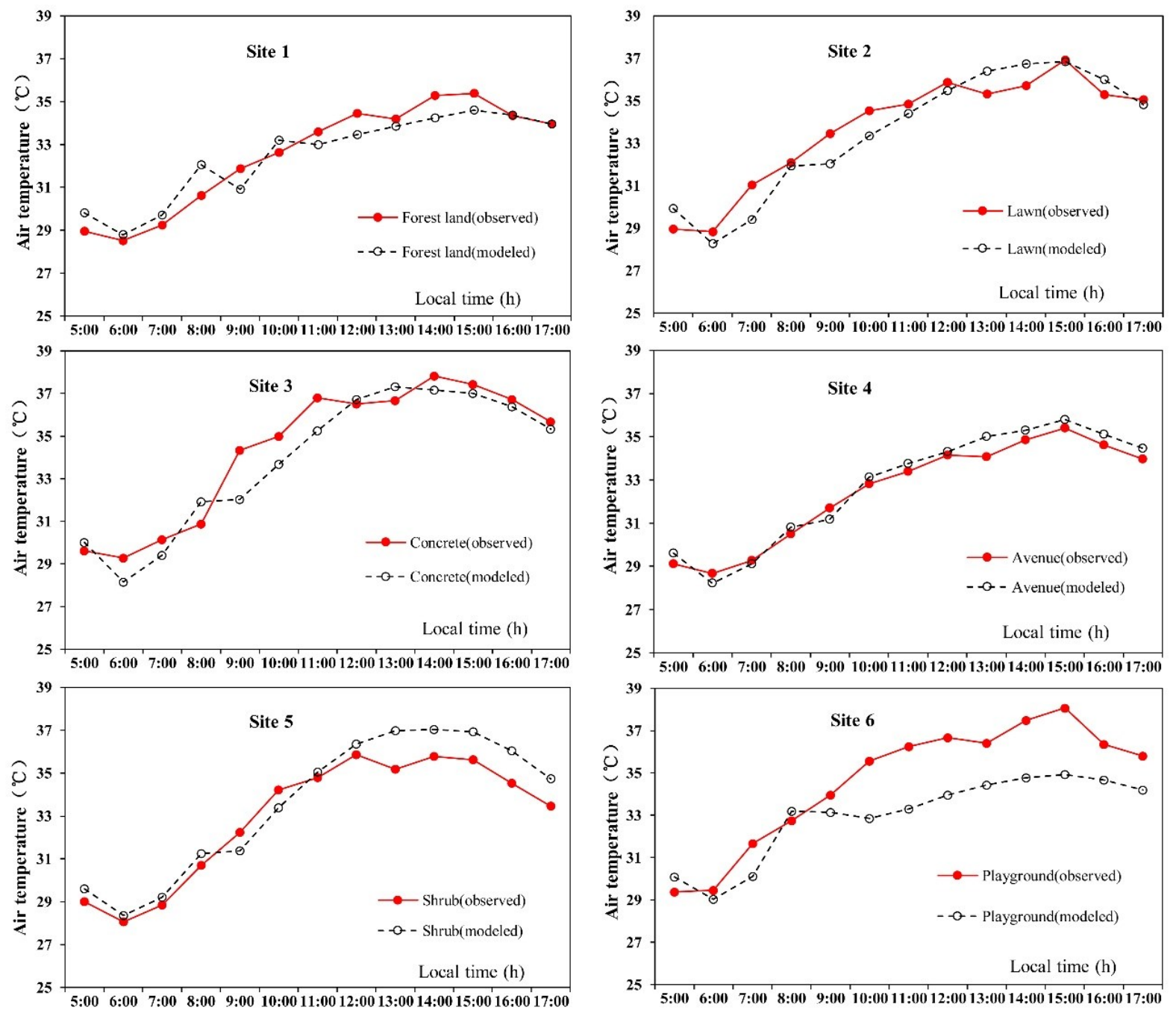

Fig. 3. Comparison of modeled and observed air temperatures at $1.5 \mathrm{~m}$ above ground on July 18,2013

Table 3 lists the key metrics of error between modeled and observed air temperatures, specifically: root mean square error (RMSE), RMSEU (unsystematic RMSE), RMSES (systematic RMSE), and the index of agreement $d$. Among these metrics, RMSES values were comparatively small, while $R M S E U$ approached the $R M S E$, indicating that the prediction error of the model was mainly systematic. A high index of agreement $(d=0.95)$ demonstrates that the ENVI-met model simulated our study area well, and in comparison with previous research (e.g., [52], [55] and [48]), air temperatures predicted in the current study were reasonable. 
Table 3 Quantitative evaluation of the error between modeled air temperatures and observed results.

\begin{tabular}{lllllll}
\hline Variable & Height & Samples & RMSES & RMSEU & RMSE & $\mathrm{d}$ \\
\hline $\mathrm{T}_{\mathrm{a}}\left({ }^{\circ} \mathrm{C}\right)$ & at $1.5 \mathrm{~m}$ & 78 & 0.43 & 1.06 & 1.14 & 0.95 \\
\hline
\end{tabular}

Sample: The simulated air temperature of six sites at 1.5 $\mathrm{m}$ for each hour from 05:00 to 17:00.

\subsection{Effect of green space on the outdoor thermal environment based on the observed data}

Our comparison of the daytime micro-meteorological characteristics of different land surfaces from 05:00 h to 17:00 h on July 18, 2013 demonstrates that green areas had exhibited a pronounced cooling effect on the study area. The mean daytime air temperature of the six sites $\left(\mathrm{T}_{\mathrm{a}}\right)$ was $33.4^{\circ} \mathrm{C}$. The mean air temperature of the forest (Site $1,32.5^{\circ} \mathrm{C}$ ) was cooler by $0.9^{\circ} \mathrm{C}$ than its corresponding $\mathrm{T}_{\mathrm{a}}$ (Fig. 4). This difference may be explained by the fact that the microclimate beneath trees is mainly controlled by radiation interception and tree evapotranspiration, which together modify the heat balance of the surrounding environment. Under the trees, the mean absorbed solar radiation was only $6.2-13.4 \%$ of that of concrete surfaces based on the observed data. As a result, the daily mean air temperature of the forest (site 1) was about $1.9^{\circ} \mathrm{C}$ lower than the mean air temperature of the concrete area (Site 3, $\left.34.4{ }^{\circ} \mathrm{C}\right)$. Statistical analysis also found a reduction in the maximum air temperature by $3.4{ }^{\circ} \mathrm{C}$ in the avenue (Site 4) and $3.2^{\circ} \mathrm{C}$ in the forest (Site 1) around 11:00 relative to the forested area (Site 1, Site 4) and the concrete area (Site 3), respectively (Fig. 4). At the same time, modeled mean air temperature $\left(33.1^{\circ} \mathrm{C}\right)$ at $1.5 \mathrm{~m}$ was lower than the observed mean $\left(33.4{ }^{\circ} \mathrm{C}\right)$. This result was in agreement with previous research reporting that the ENVI-met model has a tendency to underestimate air temperature [61], [67] and [68].

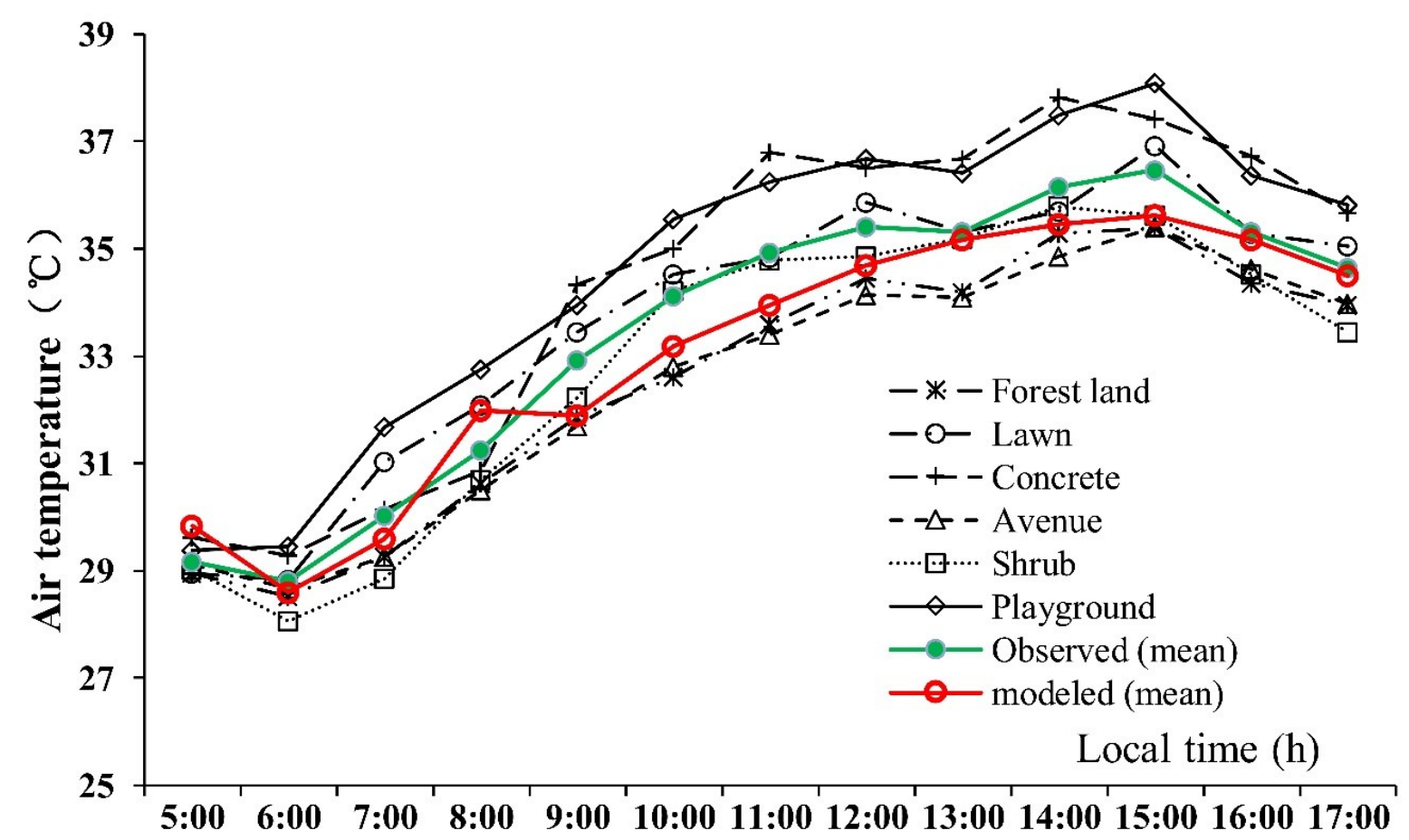

Fig. 4. Microclimate variation characteristics of each measurement point in the daytime of July 18 as well as the mean $\mathrm{T}_{1.5 \mathrm{~m}}$ of the observed and modeled for all sites. 


\subsection{Differences in outdoor thermal environment between the current and designed scenarios}

The 3D thermal environment modeled with ENVI-met for the two scenarios was first compared by calculating the daily mean $1.5 \mathrm{~m}$ air temperature and the mean air temperature in the vertical direction $(225 \mathrm{~m})$ above the study area. The following subsections outline the spatial pattern and variation characteristics of the two scenarios.

\subsubsection{Spatial variation in the daily mean thermal environment at $1.5 \mathrm{~m}$ height}

The daytime average $1.5 \mathrm{~m}$ air temperature $\left(\mathrm{T}_{1.5 \mathrm{~m}}\right)$ of the current scenario was $33.1^{\circ} \mathrm{C}$. Within our study area, one of the main hotspots with higher mean air temperature was located in front of the Aquatic Center (Fig. 1). This center extends to the north along the building canyon between Feiyimin B. and the Gym B., creating a major high-temperature hotspot behind Feiyimin B. (Figs. 1, 5a, and $\underline{6} a$ ). This hotspot can be attributed to both concrete ground cover and the effects of building positioning and wind movement. The prevailing wind came from the south (Fig. 6a). The three main air inflows in the current scenario included flows from the canyon between the Mengmingwei B. and the Library B. and the airflow from the south gate of the school along the Pingcang Road (Figs. 1 and 6a). The main warm inflow occurred at the south gate of the school, passing Zhongda Avenue and then becoming an east-west bi-directional airflow by the Teaching B. (Fig. 6a). The westerly airflow merged with the airflow along the Pingcang Road and then streamed into the playground, finally flowing out of the campus on either side of the Feiyimin B. The northsouth-oriented canyons on both sides of the Feiyimin B. likely experienced a lee effect from the buildings acting as windbreaks and also contributed to the hotspots behind the Feiyimin B. (Figs. 5a and 6a). The easterly airflow, which merged with the airflow from the northsouth-oriented canyon at the Mengmingwei B., streamed out of the campus along the Tianjin Road (Fig. 6a). No hotspots were found in the downwind direction likely due to the presence of grassland and trees around Beida B. and Gulou Park (located off campus).

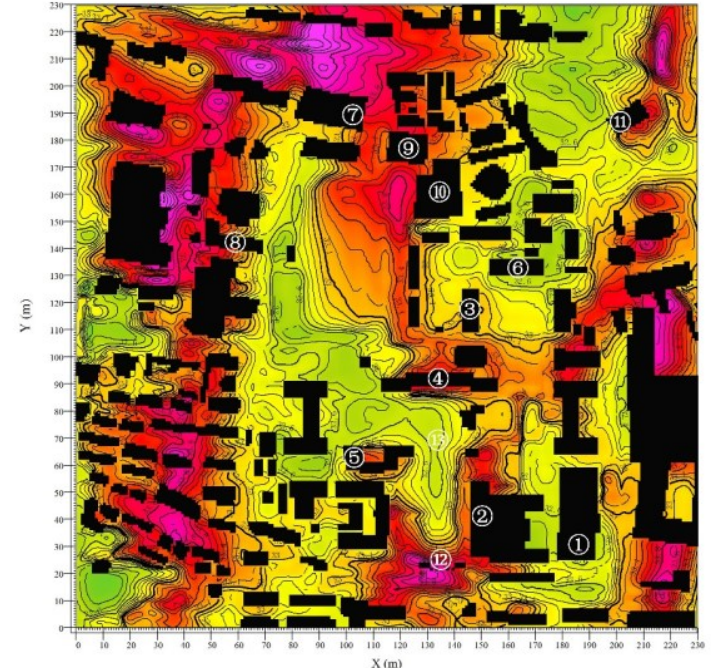

(a)

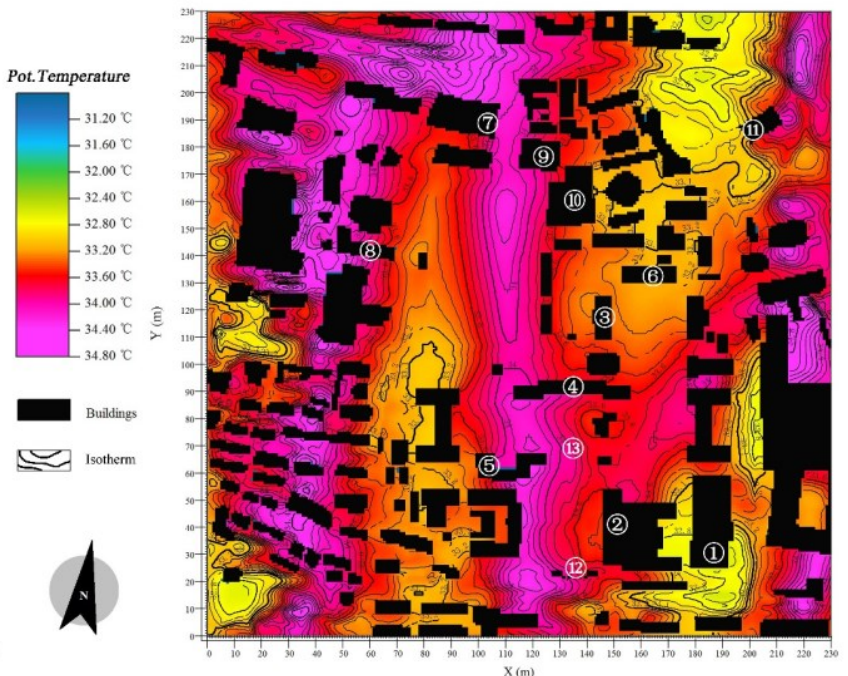

(b)

Fig. 5. Spatial pattern of mean $T_{1.5 \mathrm{~m}}$ and isotherm generated by the ENVI-met Numerical simulation from 5:00-17:00 of July 18. a) current scenario, b) designed scenario (without greenspace); (1)Mengminwei B. (2)Library B., (3)Xinan B., (4)Teaching B., (5)Zhixing B., (6) Beida B., (7)Feiyimin B,. (8)Art science B., (9)Gyms B., (10)Aquatic center B., (11)Gulou Park, (12)South gate (13)Zhongda Ave. 


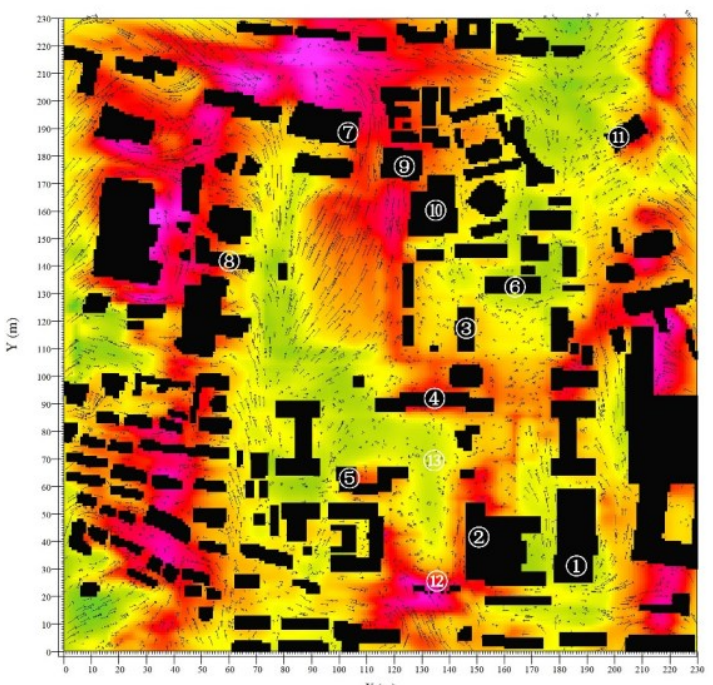

(a)

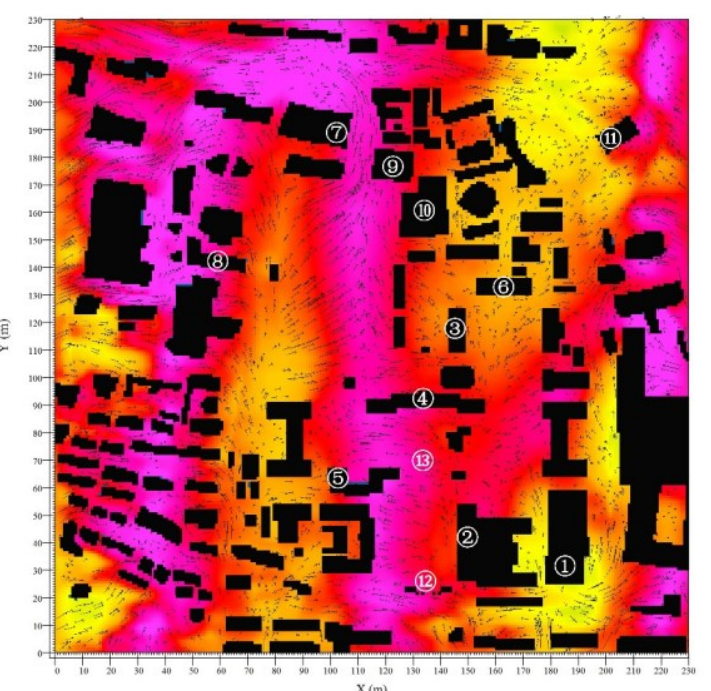

$(\mathrm{b})$

Fig 6. Spatial pattern of mean $\mathrm{W}_{1.5 \mathrm{~m}}$ and $\mathrm{T}_{1.5 \mathrm{~m}}$ generated by the ENVI-met Numerical simulation from 5:00-17:00 of July 18. a) current scenario, b) designed scenario (without greenspace); (1)Mengminwei B. (2)Library B., (3)Xinan B., (4)Teaching B., (5)Zhixing B., (6)Beida B., 7 Feiyimin B., (8)Art science B., (9)Gyms B., (10)Aquatic center B., (11)Gulou Park, (12) South gate (13)Zhongda Ave.

The playground located in the western part of the study area represented another hightemperature hotspot (Fig. 5a) due to the lack of shade and its lower terrain. This hotspot occurred in spite of the cooling effect from the cool island created by the forest in front of the Teaching B. and extended by the southerly wind flow (Figs. 5a and 6a). Two other hotspots were found in the northwestern part of the study site around the Art Science B. and at the campus south gate (Figs. 5a and 6a). These hotspots occurred due to the presence of extensive concrete surfaces and the lack of vegetation.

The coolest areas were all forested and were located around the Xinan, Zhixing and Teaching buildings (Figs. 5a and 6a), extending to the north along the playground. Another cool pocket was located between the Library and Mengminwei buildings, where the greenery was sparse, but building shade contributed to the cooling effect (Figs. 1, 5a, and 6a).

The designed scenario resulted in a mean $1.5 \mathrm{~m}$ air temperature of $33.6{ }^{\circ} \mathrm{C}$ and a maximum temperature of $35.1^{\circ} \mathrm{C}$, which were, respectively, $0.5^{\circ} \mathrm{C}$ and $0.6^{\circ} \mathrm{C}$ higher than in the current scenario (Fig. 5a and b). This increase can be attributed to changes in the landscape surface characteristics and removal of green space (Fig. 7). Between the two scenarios, few changes in the airflow direction occurred; however, average wind speed increased by $0.13 \mathrm{~m} / \mathrm{s}$ $(0.41 \mathrm{~m} / \mathrm{s}$ vs. $0.54 \mathrm{~m} / \mathrm{s})$ in the designed scenario. Removing the forest around Bainianding increased wind speed by $0.45 \mathrm{~m} / \mathrm{s}$, demonstrating that trees reduce wind speed (Fig. 6b). The absence of forest in the designed scenario caused the main warm airflow from the south of the gate to move directly to the north. This effect was gradually amplified by wind from the southwest, which elongated the hot area along the central axis of the campus and intensified the hotspot behind the Feiyimin B. (Fig. 6b). 


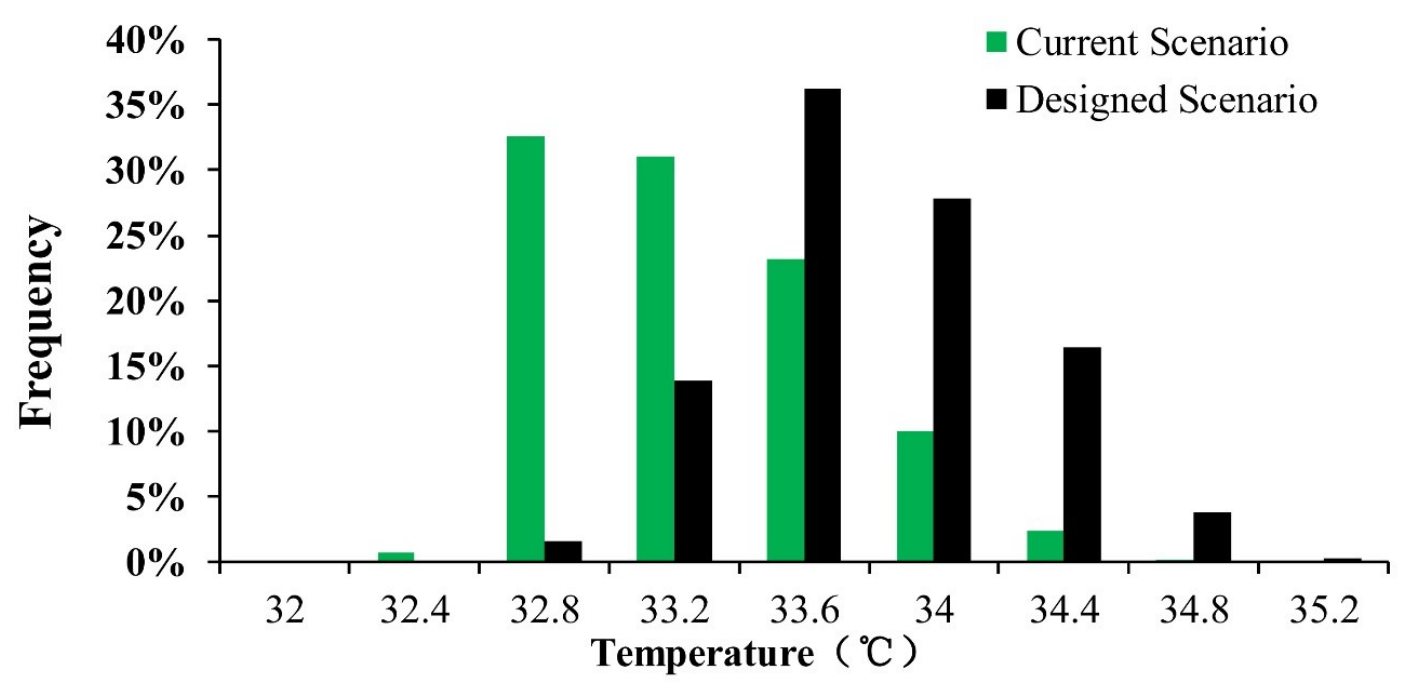

Fig. $7 \mathrm{~T}_{1.5 \mathrm{~m}}$ distribution of the grid cell-level $\mathrm{T}_{1.5 \mathrm{~m}}$ in the current and designed scenarios

To investigate the thermal differences between two scenarios further and to determine exactly where and how green spaces affected $\mathrm{T}_{1.5 \mathrm{~m}}$, the outputs of the two scenarios were spatially overlaid using ArcGIS software (Esri Inc.). Their comparison revealed that higher differences in temperature occurred in the forested area among the Xinan, Zhixing, and Teaching buildings and extended to the southeast of the playground (Fig. 8). The largest temperature increase $\left(2.0^{\circ} \mathrm{C}\right)$ in the designed scenario occurred in the forested area near Bainianding. This change was associated with the loss of trees decreasing the hot airflow from the south, the loss of cooling through evapotranspiration and shade, and accumulation of the hot air due to the blockage of the head-on airflow by the Southwest and Teaching buildings. These effects amplified the high-temperature hotspots. Air temperature also increased around the playground and to the east of the Beida B. due to the removal of green spaces. 


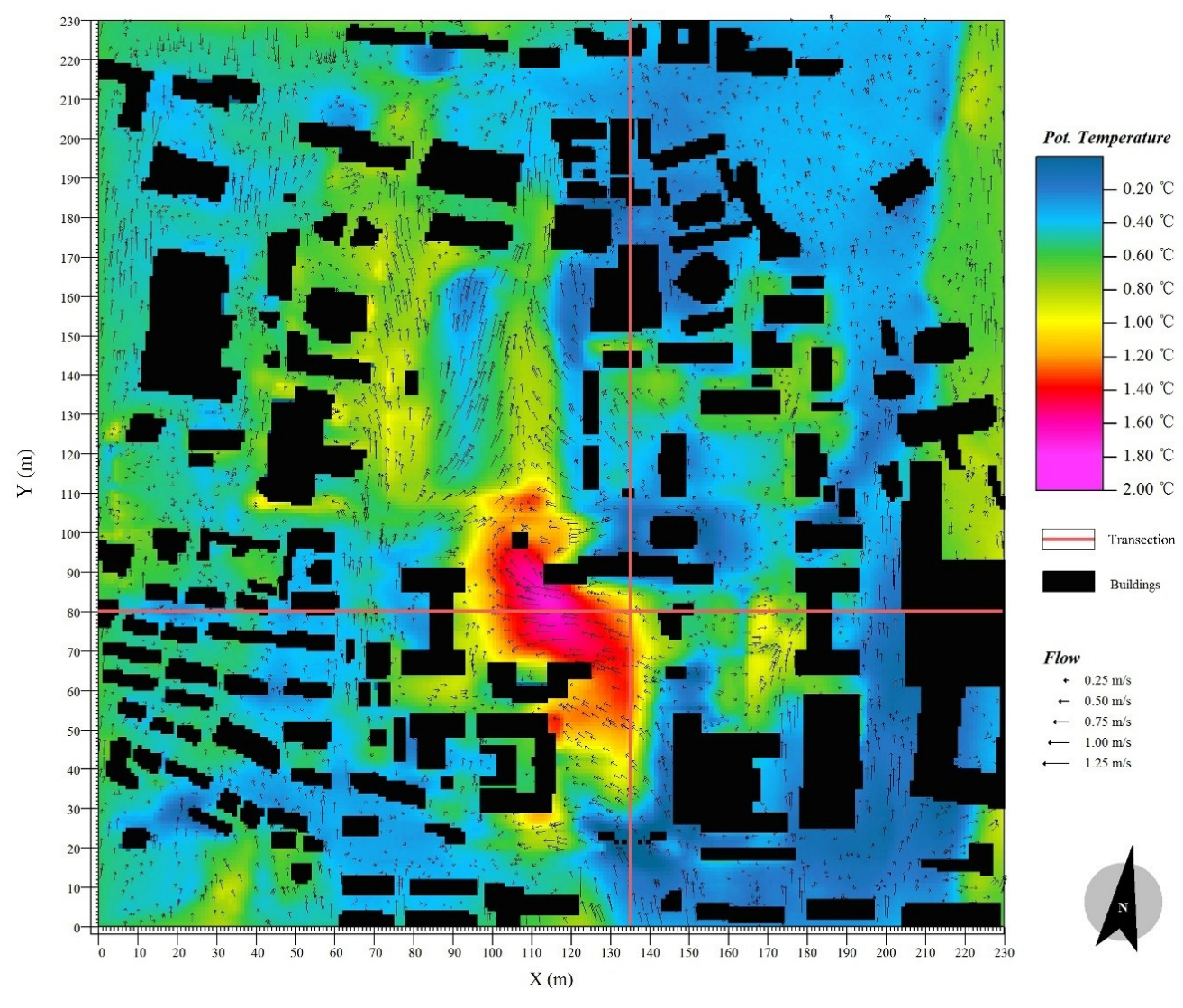

Fig. 8. Spatial changes in $\mathrm{T}_{1.5 \mathrm{~m}}$ and $\mathrm{W}_{1.5}$ for the two simulated scenarios through an overlay analysis. Red lines show two profiles at the $x$-axis 135 and $y$-axis 80 intersecting in front of the Teaching B.

\subsubsection{Differences in vertical daily mean air temperatures between the current and designed scenarios}

Changes in land surface between the current and designed scenarios influenced the study area's thermal environment both vertically and horizontally. Two profiles were selected for the vertical analysis (Fig. 8): a cross section located on the $x$-axis $(x=135)$ that runs along the north-south direction of Zhongda Avenue, and a cross section on the $y$-axis $(\mathrm{y}=80)$ that runs across the landmark Bainianding. These two profiles intersected at the forested area in front of the Teaching B.

Two distinct temperature-wind profiles were detected along the $x$-axis cross section ( $\underline{\text { Fig. } 9}$ ). In both scenarios, the prevailing wind was southerly with laminar airflow. However, in the current scenario, the airflow from the urban canopy was oblique to the ground (Fig. 8), because in the daytime, the Xinan B. heated up quickly due to the underlying building surface. Hot airflow rose and shifted to the east because of the airflow from the Pingcang Road. Finally, temperature decreased with increasing height. An increase in airflow reduced the atmospheric pressure of the original area, with the upper layer of cold air in the city canopy sinking and thus initiating vertical circulation flow. The airflow was occurring on the edge of a clockwise vortex, after which wind blew obliquely to the ground. In the designed scenario, the airflow direction blew upward, with an increase in wind velocity. Because there was no green space in this scenario, the near ground temperature increased, causing the air to blow upwards, with the high-temperature range expanding. 

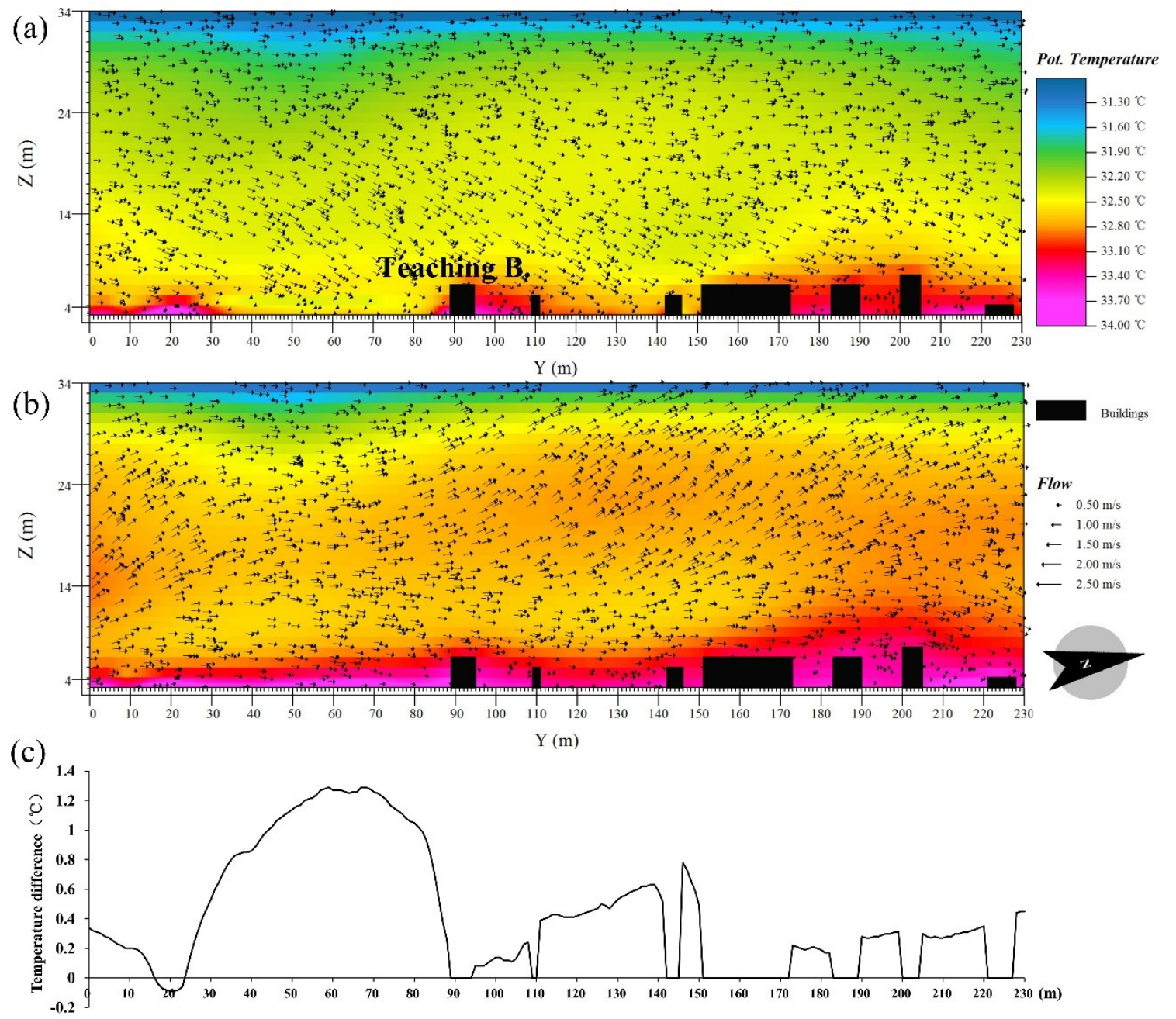

Fig. 9. Vertical section of numerical simulation of air temperature and wind velocity vector along the Zhongda Ave. from south to north for (a) the current scenario, (b) the designed scenario, (c) the temperature difference at $1.5 \mathrm{~m}$ along the profile

In the current scenario, lee effect zones were present behind the building, causing the air temperature on the leeward side of the building to be significantly higher than on the windward side (Fig. 9a). In the designed scenario, the lee effect zone still existed; however, the temperature increased significantly in front of and behind the building, with a clearly greater hot spot size. Furthermore, the air temperature gradient decreased with increasing vertical height in the current scenario (Fig. 9a). However, after the removal of green space, an exaggerated "inversion" effect was present above the Teaching B. (around Y $=90-110$ ) when $\mathrm{Z}$ was greater than 14 (Fig. 9b). The temperature difference at $1.5 \mathrm{~m}$ along the south-north vertical profile (Fig. 9c) indicated that $\mathrm{T}_{\mathrm{a}}$ would increase in most places after the removal of green spaces. The greatest increase (by $1.3^{\circ} \mathrm{C}$ ) occurred along the previously forested Zhongda Ave.

Along the $x$-axis cross section from west to east, vortex airflow perpendicular to the prevailing wind direction was detected in both profiles, with two clear vortices in each selected transection (Fig. 10). After the removal of green space, the increased difference between land surface temperature and the above air temperature caused an increase in wind velocity, with vortex activities becoming more intense, resulting in a wider range of vortices. 

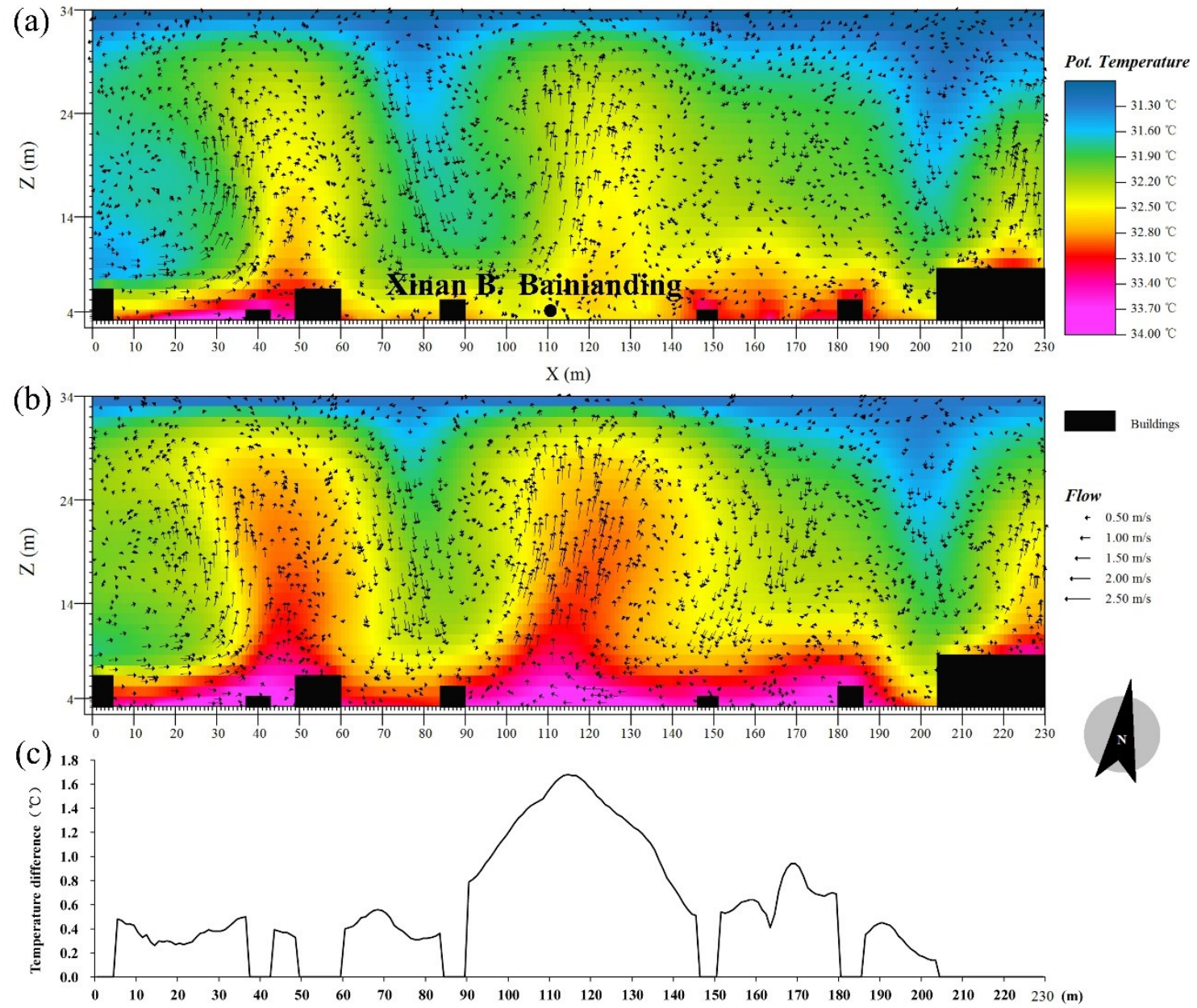

Fig. 10. Vertical section of numerical simulation of air temperature and wind velocity vector from west to east for current scenario (a) and the designed scenario (b), as well as the temperature difference at $1.5 \mathrm{~m}$ along the profile (c).

The emergence of vertical-circulation airflow was caused by the adjacent high-temperature and low-temperature regions at the ground level (Fig. 10a). Under the current scenario, rising hot airflow from the Xinan B. mixed with cool air from the forested land, generating many vortices in the urban canopy. After the removal of green space, the energy exchange between the ground and air became more intense, and the corresponding vortex activities were more severe, with an intensified temperature increase in front of the Xinan B. and around Bainianding causing high temperature areas to expand significantly. A distinct "heat island" was created, especially around the Bainianding area $(X=110)$, where high-temperature airflow created a large vortex. The temperature difference at $1.5 \mathrm{~m}$ along the west-east vertical profile (Fig. 10c) indicated that the simulated removal the green spaces caused $T_{a}$ to increase by $1.7^{\circ} \mathrm{C}$.

Analysis of the change to the thermal environment in the vertical direction showed that hightemperature areas tended to occur around the buildings and areas with fewer green spaces under the current scenario. However, after the removal of green spaces in the designed scenario, air temperature, wind velocity and the size of the high-temperature area all increased, with the energy exchange between the ground and air intensifying due to the 
underlying surface changes. These results corroborate the assumption that green spaces on campus mitigate high temperatures. However, the pattern of building placement also contributed to the differences between the two scenarios.

\subsection{Cooling benefits of green spaces at the mean building height}

To calculate the energy savings from the cooling effect of vegetation on campus throughout a summer day using formulas (1) and (2), the vertical height was first defined as a mean building height of $30 \mathrm{~m}$. This height takes into account the analysis of the vertical variation in the daily mean thermal environment, which showed that the layer was stable at the mean building height layer of $30 \mathrm{~m}$. Furthermore, there was no "inversion" phenomenon under the two scenarios with circulation.

Next, nine horizontal slice profiles were established at various heights in the study area and a regression analysis was performed based on average daily temperatures in each height (Fig. 11). Using formula (1) and the developed regression statistical model, the daily mean accumulative temperature reduction that was generated by the green spaces was then calculated based on formula (3):

$$
\begin{aligned}
& \text { equation }(3) \\
& \begin{aligned}
\Delta \mathrm{T}_{30}= & \int_{0}^{30}[(g(h)-f(h)] d h \\
= & \int_{0}^{30}\left[\left(-0.0095 h^{2}-0.0042 h+33.67\right)-\left(-0.0062 h^{2}\right.\right. \\
& -0.0176 h+33.124)] d h
\end{aligned}
\end{aligned}
$$

These calculations showed that, compared with the designed scenario where all of the green spaces were removed, the current scenario contributed to a daily mean $14.4{ }^{\circ} \mathrm{C}$ cumulative reduction in temperature from ground level to a height of $30 \mathrm{~m}$.

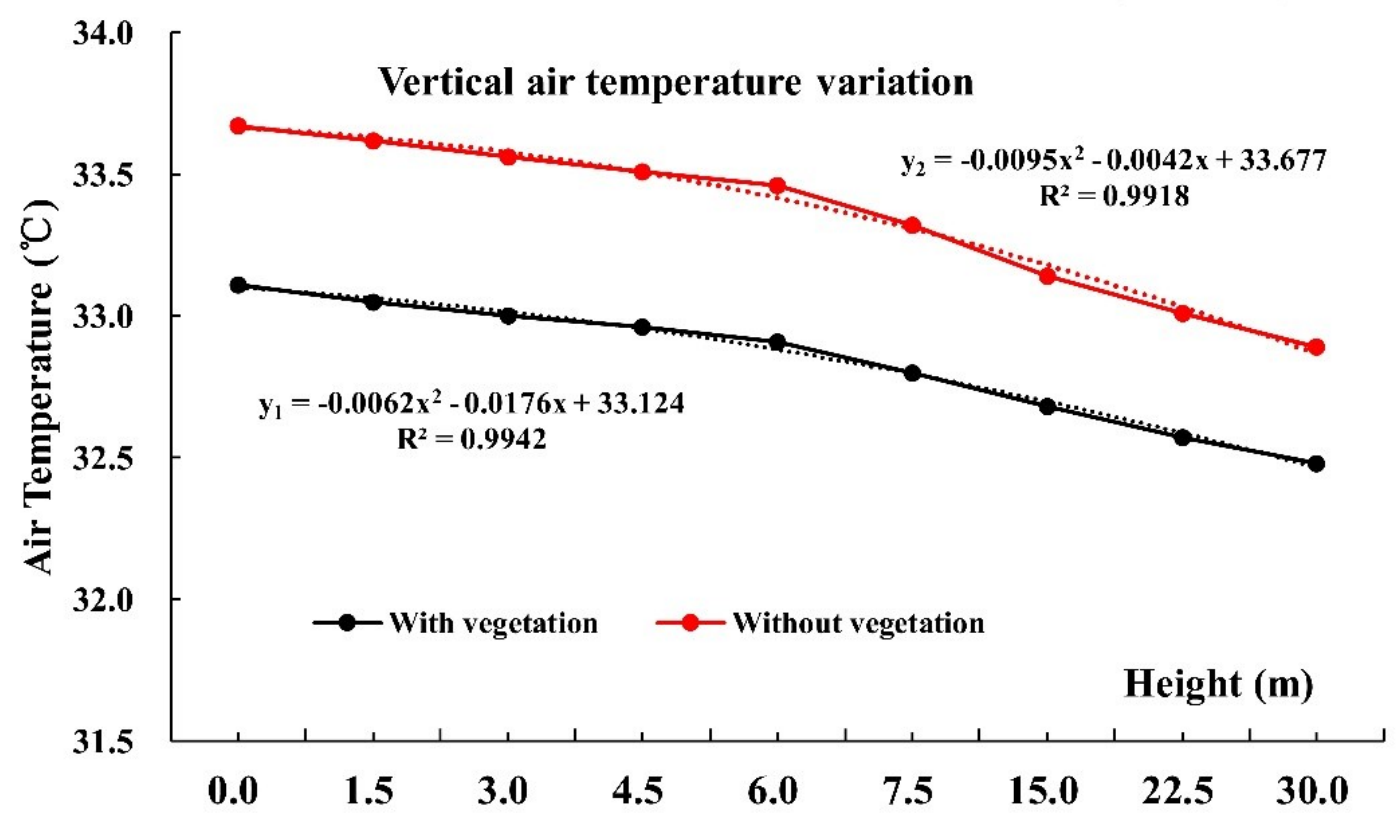

Fig. 11 Vertical air temperature distribution with the height change and the regression analysis. 
Then, using the formulas (2) and (3), the total energy savings from the vegetation cooling effect of the campus were estimated using formula (4):

equation(4)

$\Delta Q_{30}=c m \Delta \mathrm{T}_{30}=c \rho s \int_{0}^{30}[g(h)-f(h)] d h$

These results showed that cooling energy was about $5.2 \mathrm{~W} / \mathrm{m}^{2}$ in the study area, which was higher than $5 \mathrm{~W} / \mathrm{m}^{2}$ estimated by Sugawara et al. [40] in a park of $0.58 \mathrm{~km}^{2}$ area. Thus, for the total study area $\left(1.9 \times 10^{5} \mathrm{~m}^{2}\right.$, excluding the built-up area) the cooling effect of vegetation was equal to $0.99 \times 10^{6} \mathrm{~W}$ during the daytime (i.e., daylight hours) of the summer. If a room-scale air conditioner has the cooling ability of $2.8 \times 10^{3} \mathrm{~W}$ [40], the fragmented green spaces would have the same cooling ability as 356 air conditioners, and could save $1.3 \times 10^{4} \mathrm{~kW}$ h energy compared to the same area lacking green spaces.

\section{Conclusions}

Supported by the in-situ measurements and 3D ENVI-met microclimate simulations, this study demonstrated that green spaces on the Gulou campus positively affect microclimate on hot summer days and mitigate high air temperatures. The analysis of the daytime 3D temperature profile revealed that removal of green spaces changed the spatial pattern of hightemperature hotspots at $1.5 \mathrm{~m}$ above ground level and eliminated the cool island effect, increasing the daily mean temperature by $0.5^{\circ} \mathrm{C}$.

The study also found that green spaces provide vertical cooling within the mean building height, as quantified by the regression analysis. The results indicate a mean $14.4{ }^{\circ} \mathrm{C}$ cumulative reduction in temperature during the day from the ground level to $30 \mathrm{~m}$ height in the current scenario compared to the designed scenario where all green spaces were removed. Using a simple energy equation, the cooling performance of the vegetation on campus was estimated to be equivalent to 356 room-scale air-conditioners and $1.3 \times 10^{4} \mathrm{~kW}$ h of energy.

It should be acknowledged, however, that this research was based on a controlled simulation, assuming complete removal of all green spaces and a vertical boundary at $30 \mathrm{~m}$, which might not accurately reflect the energy savings in real world conditions. The conversion of green spaces to land cover types other than concrete could also produce different results. The height of the near-surface atmosphere might also change depending on the specific climate or seasons of the region [38]. Lastly, the sky view factor (SVF), previously reported to influence microclimate [69] and [70], would also differ between scenarios with and without green space and thus affect their differences in microclimate. In particular, even though we strengthened the numerical ENVI-met simulation by using on-site observations, some parameters used in the model (e.g., urban terrain) were not considered. Despite these limitations, our findings confirm that green spaces provide cooling services, and this study provides a novel way of quantifying the cumulative effect of small fragmented green patches while considering the effect of tree shade and evapotranspiration cooling. Our analysis clearly expands on preceding cooling energy work, which only considered the cooling effect of tree shade [1], [29], [71] and [72].

We developed a straightforward approach for understanding the value of green spaces by simulating the 3D thermal environment of the real-world landscape and a de-vegetated scenario to quantify the cooling potential. Lack of knowledge about the characteristics and magnitude of cooling services provided by fragmented green spaces at fine landscape scales 
often results in people overlooking their values and having little incentive to protect them. This issue leads to further losses of green space, amplified urban heat island effects, and increased energy demand for artificial cooling devices. Thus, it is important to educate the public about the value of cooling services provided by green spaces to mitigate further loss to artificial surfaces.

Although the cooling effects and energy savings are location-specific [73] and [74], the framework provided in this research can be applied universally beyond the study area. The equations developed here constitute a potentially useful and practical method for quantifying energy saving from green spaces at different spatio-temporal scales (e.g., neighborhood to city or regional scales over a whole summer season or one year), when the $3 \mathrm{D}$ thermal environment is simulated well by selecting an appropriate model (e.g., WRF, Weather and Research Forecasting, or ENVI-met) [73] and [75]. Knowledge about the cooling services provided by green spaces will help decision-makers and planners to understand the consequences of removing vegetation. This knowledge will also facilitate the protection, planning, and design of green spaces to maximize their benefits through improving the thermal environment at the neighborhood, city, and regional scale.

\section{Acknowledgments}

This research was supported by the National Natural Science Foundations of China (Nos. 31170444 and 51478217), and the open fund from the State Key Laboratory of Urban and Regional Ecology (SKLURE). The authors thank Feng XU, Yulong BAN, Weijiao YAN, Wenbin XU and all other members who helped to conduct the field surveys.

\section{References}

[1] Akbari H, Pomerantz M, Taha H. Cool surfaces and shade trees to reduce energy use and improve air quality in urban areas. Solar energy, 2001, 70(3): 295-310.

[2] Akbari H. Shade trees reduce building energy use and $\mathrm{CO}_{2}$ emissions from power plants. Environmental pollution, 2002, 116: S119-S126.

[3] Golden J S. The built environment induced urban heat island effect in rapidly urbanizing arid regions-a sustainable urban engineering complexity. Environmental Sciences, 2004, 1(4): 321-349.

[4] Grimmond S. Urbanization and global environmental change: local effects of urban warming. The Geographical Journal, 2007, 173(1): 83-88.

[5] Radhi, H. Sharples, S. Quantifying the domestic energy electricity consumption for air conditioning due to urban heat islands in hot arid regions. Applied Energy, 2013, 112 : 371-380

[6] C.B. Li, J.J. Zhou, Y.J. Cao, J. Zhong, Y. Liu, C.Q. Kang, Y. Tan. Interaction between urban microclimate and electric air-conditioning energy consumption during high temperature season Appl Energy, 117 (2014), pp. 49-156

[7] Y. Kikegawa, Y. Genchi, H. Yoshikado, H. Kondo. Development of a numerical simulation system toward comprehensive assessments of urban warming countermeasures including their impacts upon the urban buildings' energy demands. Appl Energy, 76 (2003), p. 449

[8] A. Chudnovsky, E. Ben-Dor, H. Saaroni Diurnal thermal behavior of selected urban objects using remote sensing measurements. Energy Build, 36 (11) (2004), pp. 10631074 
[9] T. Ihara, Y. Kikegawa, K. Asahi, Y. Genchi, H. Kondo. Changes in year-round air temperature and annual energy consumption in office building areas by urban heat-island countermeasures and energy-saving measures. Applied Energy, 85 (1) (2008), pp. 12-25.

[10] Y. Zhou, J.M. Shepherd. Atlanta's urban heat island under extreme heat conditions and potential mitigation strategies. Nat Hazards, 52 (3) (2010), pp. 639-668

[11]. Z.H. Wang, X. Zhao, J. Yang, J. Song. Cooling and energy saving potentials of shade trees and urban lawns in a desert city. Appl Energy, 161 (2016), pp. 437-444

[12] L. Shashua-Bar, D. Pearlmutter, E. Erell. The influence of trees and grass on outdoor thermal comfort in a hot-arid environment. Int J Climatol, 31 (10) (2011), pp. 1498-1506

[13] F.H. Kong, W.J. Yan, G. Zheng, H.W. Yin, G. Cavan, W.F. Zhan, N. Zhang, L. Cheng. Retrieval of three-dimensional tree canopy and shade using terrestrial laser scanning (TLS) data to analyze the cooling effect of vegetation. Agric Forest Meteorol, 217 (2016), pp. 22-34

[14] G.D. Jenerette, S.L. Harlan, W.L. Stefanov, C.A. Martin. Ecosystem services and urban heat riskscape moderation: water, green spaces, and social inequality in Phoenix, USA. Ecol Appl, 21 (7) (2011), pp. 2637-2651

[15] J. Song, Z.H. Wang. Impacts of mesic and xeric urban vegetation on outdoor thermal comfort and microclimate in Phoenix, AZ. Build Environ, 94 (2015), pp. 558-568

[16] A. Dimoudi, M. Nikolopoulou. Vegetation in the urban environment: microclimatic analysis and benefits. Energy Build, 35 (2003), pp. 69-76

[17] C. Yu, W.N. Hien. Thermal benefits of city parks. Energy Build, 38 (2) (2006), pp. 105120

[18] I. Zoulia, M. Santamouris, A. Dimoudi. Monitoring the effect of urban green areas on the heat island in Athens. Environ Monit Assess, 156 (1-4) (2009), pp. 275-292

[19] S. Hamada, T. Ohta. Seasonal variations in the cooling effect of urban green areas on surrounding urban areas. Urban For Urban Green, 9 (1) (2010), pp. 15-24

[20] T. Susca, S.R. Gaffin, G.R. Dell'Osso. Positive effects of vegetation: urban heat island and green roofs. Environ Pollut, 159 (8) (2011), pp. 2119-2126

[21] A. Wania, M. Bruse, N.G. Blond, C. Webera. Analysing the influence of different street vegetation on traffic-induced particle dispersion using microscale simulations. J Environ Manage, 94 (1) (2012), pp. 91-101

[22] Z.H. Wang. Monte Carlo simulations of radiative heat exchange in a street canyon with trees. Sol Energy, 110 (2014), pp. 704-713

[23] W.D. Solecki, C. Rosenzweig, L. Parshall, G. Pope, M. Clark, J. Cox, M. Wiencke. Mitigation of the heat island effect in urban New Jersey. Global Environ Change Part B Environ Hazards, 6 (1) (2005), pp. 39-49

[24] F. Kong, H. Yin, P. James, L.R. Hutyra, H.S. He. Effects of spatial pattern of greenspace on urban cooling in a large metropolitan area of eastern China. Landscape Urban Plan, 128 (2014), pp. 35-47.

[25] J. Declet-Barreto, A.J. Brazel, C.A. Martin, W.T. Chow, S.L. Harlan. Creating the park cool island in an inner-city neighborhood: heat mitigation strategy for Phoenix, AZ. Urban Ecosyst, 16 (3) (2013), pp. 617-635

[26] F. Skoulika, M. Santamouris, D. Kolokotsa, N. Boemi. On the thermal characteristics and the mitigation potential of a medium size urban park in Athens, Greece. Landscape Urban Plan, 123 (2014), pp. 73-86

[27] Y. Ohashi, T. Ihara, Y. Kikegawa, N. Sugiyama Numerical simulations of influence of heat island countermeasures on outdoor human heat stress in the 23 wards of Tokyo, Japan. Energy Build, 114 (2016), pp. 101-104

[28] V.T. Ca, T. Asaeda, E.M. Abu. Reductions in air conditioning energy caused by a nearby park. Energy Build, 29 (1998), pp. 83-92 
[29] R. Pandit, D.N. Laband. Energy savings from tree shade. Ecol Econ, 69 (6) (2010), pp. $1324-1329$

[30] M. Srivanit, K. Hokao. Evaluating the cooling effects of greening for improving the outdoor thermal environment at an institutional campus in the summer. Build Environ, 66 (2013), pp. 158-172

[31] C.Y. Jim. Air-conditioning energy consumption due to green roofs with different building thermal insulation. Appl Energy, 128 (2014), pp. 49-59

[32] J. Kim, T. Hong, J. Jeong, C. Koo, K. Jeong. An optimization model for selecting the optimal green systems by considering the thermal comfort and energy consumption. Appl Energy, 169 (2016), pp. 682-695

[33] H. Akbari, S. Konopacki Calculating energy-saving potentials of heat-island reduction strategies. Energy Policy, 33 (6) (2005), pp. 721-756

[34] H.F. Castleton, V. Stovin, S.B.M. Beck, J.B. Davison. Green roofs; building energy savings and the potential for retrofit. Energy Build, 42 (10) (2010), pp. 1528-1591

[35] M. Sawka, A.A. Millward, J. Mckay, M. Sarkovich. Growing summer energy conservation through residential tree planting. Landscape Urban Plan, 113 (2013), pp. 19

[36] Y. Wang, F. Bakker, R. de Groot, H. Wörtche. Effect of ecosystem services provided by urban green infrastructure on indoor environment: A literature review. Build Environ, 77 (2014), pp. 88-100

[37] U. Berardi, A. Ghaffarian Hoseini, Hoseini.A. Ghaffarian. State-of-the-art analysis of the environmental benefits of green roofs. Appl Energy, 115 (2014), pp. 411-428

38] P.C. West, G.T. Narisma, C.C. Barford, C.J. Kucharik, J.A. Foley. An alternative approach for quantifying climate regulation by ecosystems. Front Ecol Environ, 9 (2) (2010), pp. 126-133

[39] F.J. Escobedo, T. Kroeger, J.E. Wagner. Urban forests and pollution mitigation: analyzing ecosystem services and disservices. Environ Pollut, 159 (8) (2011), pp. 20782087

[40] H. Sugawara, H. Tanaka, K.I. Narita, T. Nakano, T. Mikami. How much cool air does an urban green park produce? Geogr Rep Tokyo Metropolitan Univ, 43 (2008), pp. 83-89

[41] F. Kong, H. Yin, N. Nakagoshi. Using GIS and landscape metrics in the hedonic price modeling of the amenity value of urban green space: a case study in Jinan City, China. Landscape Urban Plan, 79 (2007), pp. 240-252

[42] S. Guhathakurta, P. Gober. Residential land use, the urban heat island, and water use in Phoenix: a path analysis. J Plan Educ Res, 30 (1) (2010), pp. 40-51

[43] W. Zhou, G. Huang, M.L. Cadenasso. Does spatial configuration matter? Understanding the effects of land cover pattern on land surface temperature in urban landscapes. Landscape Urban Plan, 102 (2011), pp. 54-63

[44] G.B. Bonan. The microclimates of a suburban Colorado (USA) landscape and implications for planning and design. Landscape Urban Plan, 49 (3) (2000), pp. 97-114

[45] B. Stone, J.M. Norman. Land use planning and surface heat island formation: a parcelbased radiation flux approach. Atmos Environ, 40 (19) (2006), pp. 3561-3573

[46] M.A. Hart, D.J. Sailor. Quantifying the influence of land-use and surface characteristics on spatial variability in the urban heat island. Theor Appl Climatol, 95 (3-4) (2009), pp. 397-406

[47] B. Paramita, H. Fukuda. Study on the affect of aspect building form and layout case study: Honjo Nishi Danchi, Yahatanishi, Kitakyushu-Fukuoka. Proc Environ Sci, 17 (2013), pp. 767-774 
[48] A. Middel, K. Häb, A.J. Brazel, C.A. Martind, S. Guhathakurta. Impact of urban form and design on mid-afternoon microclimate in Phoenix Local Climate Zones. Landscape Urban Plan, 122 (2014), pp. 16-28

[49] E. Ng, L. Chen, Y. Wang, C. Yuan. A study on the cooling effects of greening in a highdensity city: an experience from Hong Kong. Build Environ, 47 (2012), pp. 256-271

[50] M. Bruse, H. Fleer. Simulating surface-plant-air interactions inside urban environments with a three dimensional numerical model. Environ Modell Softw, 13 (3) (1998), pp. 373-384

[51] F. Ali-Toudert, H. Mayer. Effects of asymmetry, galleries, overhanging facades and vegetation on thermal comfort in urban street canyons. Sol Energy, 81 (2007), pp. 742754

[52] W.T.L. Chow, R.L. Pope, C.A. Martin, A.J. Brazel. Observing and modeling the nocturnal park cool island of an arid city: horizontal and vertical impacts. Theor Appl Climatol, 103 (1-2) (2011), pp. 197-211

[53] C. Skelhorn, S. Lindley, G. Levermore. The impact of vegetation types on air and surface temperatures in a temperate city: a fine scale assessment in Manchester, UK. Landscape Urban Plan, 121 (2014), pp. 129-140

[54] K. Perini, A. Magliocco. Effects of vegetation, urban density, building height, and atmospheric conditions on local temperatures and thermal comfort. Urban For Urban Green, 13 (3) (2014), pp. 495-506

[55] M. Samaali, D. Courault, M. Bruse, A. Oliosoa, R. Occelli. Analysis of a 3D boundary layer model at local scale: validation on soybean surface radiative measurements. Atmos Res, 85 (2) (2007), pp. 183-198

[56] Nanjing Municipal Statistics Bureau. Nanjing statistical yearbook. China Statistics Press, Beijing, China (2010) [in Chinese]

[57] X.Z. Xu, Y.F. Zheng, J.F. Yin, R.J. Wu. Characteristics of high temperature and heat wave in Nanjing City and their impacts on human health. Chin J Ecol, 30 (12) (2011), pp. $2815-2820$

[58] P. Conry, A. Sharma, M.J. Potosnak, L.S. Leo, E. Bensman, J.J. Hellmann, H.J. Fernando. Chicago's heat island and climate change: bridging the scales via dynamical downscaling. J Appl Meteorol Clim, 54 (7) (2015), pp. 1430-1448

[59] S. Huttner. Further development and application of the 3D microclimate simulation ENVI-met. Johannes Gutenberg-Universität, Mainz (2012)

[60] F. Ali-Toudert. Dependence of outdoor thermal comfort on street design in hot and dry climate. Doctoral dissertation Universitätsbibliothek Freiburg (2005)

[61] W.T.L. Chow, J. Brazel. Assessing xeriscaping as a sustainable heat island mitigation approach for a desert city. Build Environ, 47 (2012), pp. 170-181

[62] GB 50176-93. Thermal design code for civil building. China Building Industry Press (1993)

[63] X. Yang, L. Zhao, M. Bruse, Q. Meng. Evaluation of a microclimate model for predicting the thermal behavior of different ground surfaces. Build Environ, 60 (2013), pp. 93-104

[64] C.J. Willmott. Some comments on the evaluation of model performance. Bull Am Meteorol Soc, 63 (11) (1982), pp. 1309-1313

[65] R. Emmanuel, H. Rosenlund, E. Johansson. Urban shading-a design option for the tropics? A study in Colombo, Sri Lanka. Int J Climatol, 27 (14) (2007), pp. 1995-2004

[66] Y. Wang, F. Bakker, R.D. Groot, H. Wortche, R. Leemans. Effects of urban trees on local outdoor microclimate: synthesizing field measurements by numerical modelling. Urban Ecosyst, 18 (2015), pp. 1-27 
[67] D.N. Laband, J.P. Sophocleus. An experimental analysis of the impact of tree shade on electricity consumption. J Arboric, 35 (4) (2009), p. 197

[68] A.J. Arnfield. Two decades of urban climate research: a review of turbulence, exchanges of energy and water, and the urban heat island. Int J Climatol, 23 (1) (2003), pp. 1-26

[69] M.K. Svensson. Sky view factor analysis-implications for urban air temperature differences. Meteorol Appl, 11 (03) (2004), pp. 201-211

[70] L. Chen, E. Ng, X. An, C. Ren, M. Lee, U. Wang, Z. He. Sky view factor analysis of street canyons and its implications for daytime intra-urban air temperature differentials in high-rise, high-density urban areas of Hong Kong: a GIS-based simulation approach. Int J Climatol, 32 (1) (2012), pp. 121-136

[71] J.R. Simpson. Improved estimates of tree-shade effects on residential energy use. Energy Build, 34 (10) (2002), pp. 1067-1076

[72] Y. Ko, J.H. Lee, E.G. McPherson, L.A. Roman. Long-term monitoring of Sacramento Shade program trees: tree survival, growth and energy-saving performance. Landscape Urban Plan, 143 (2015), pp. 183-191

[73] Y. Kikegawa, Y. Genchi, H. Kondo, K. Hanaki. Impacts of city-block-scale countermeasures against urban heat-island phenomena upon a buildings energyconsumption for air-conditioning. Appl Energy, 83 (2006), pp. 649-668

[74] Y. Hirano, T. Fujita. Evaluation of the impact of the urban heat island on residential and commercial energy consumption in Tokyo. Energy, 37 (1) (2012), pp. 371-383

[75] J. Yang, H. Liu, J. Sun, Y. Zhu, X. Wang, Z. Xiong, W. Jiang. Further development of the regional boundary layer model to study the impacts of greenery on the urban thermal environment. J Appl Meteorol Climatol, 54 (1) (2015), pp. 137-152 